\title{
Design of the SHAPE-2 study: the effect of physical activity, in addition to weight loss, on biomarkers of postmenopausal breast cancer risk
}

Willemijn AM van Gemert ${ }^{*}$, Jolein I lestra ${ }^{1}$, Albertine J Schuit ${ }^{2,3}$, Anne M May ${ }^{1}$, Tim Takken ${ }^{4,5}$, Wouter B Veldhuis ${ }^{6}$, Job van der Palen ${ }^{7,8}$, Harriët Wittink ${ }^{9}$, Petra HM Peeters ${ }^{1}$ and Evelyn M Monninkhof ${ }^{1}$

\begin{abstract}
Background: Physical inactivity and overweight are two known risk factors for postmenopausal breast cancer. Former exercise intervention studies showed that physical activity influences sex hormone levels, known to be related to postmenopausal breast cancer, mainly when concordant loss of body weight was achieved. The question remains whether there is an additional beneficial effect of physical activity when weight loss is reached. The aim of this study is to investigate the effect attributable to exercise on postmenopausal breast cancer risk biomarkers, when equivalent weight loss is achieved compared with diet-induced weight loss.

Design: The SHAPE-2 study is a three-armed, multicentre trial. 243 sedentary, postmenopausal women who are overweight or obese (BMI 25-35 kg/m²) are enrolled. After a 4-6 week run-in period, wherein a baseline diet is prescribed, women are randomly allocated to (1) a diet group, (2) an exercise group or (3) a control group. The aim of both intervention groups is to lose an amount of 5-6 kg body weight in 10-14 weeks. The diet group follows an energy restricted diet and maintains the habitual physical activity level. The exercise group participates in a 16-week endurance and strength training programme of 4 hours per week. Furthermore, they are prescribed a moderate caloric restriction. The control group is asked to maintain body weight and continue the run-in baseline diet. Measurements include blood sampling, questionnaires, anthropometrics (weight, height, waist and hip circumference), maximal cycle exercise test $\left(\mathrm{VO}_{2 \text { peak }}\right), \mathrm{DEXA}$-scan (body composition) and abdominal MRI (subcutaneous and visceral fat). Primary outcomes are serum levels of oestradiol, oestrone, testosterone and sex hormone binding globulin (SHBG).
\end{abstract}

Discussion: This study will give insight in the potential attributable effect of physical activity on breast cancer risk biomarkers and whether this effect is mediated by changes in body composition, in postmenopausal women. Eventually this may lead to the design of specific lifestyle guidelines for prevention of breast cancer.

Trial registration: The SHAPE-2 study is registered in the register of clinicaltrials.gov, Identifier: NCT01511276.

\section{Background}

There is strong evidence that physical inactivity is associated with a higher postmenopausal breast cancer risk $[1,2]$. In contrast to most other risk factors, physical activity provides an opportunity for primary prevention.

The causal pathway through which exercise influences breast cancer risk is hypothesized to be predominantly

\footnotetext{
* Correspondence: w.vangemert@umcutrecht.nl

'Julius Center for Health Sciences and Primary Care, University Medical Center Utrecht, P.O. Box 85500 Hp, Str. 6.131, 3508 GA, Utrecht, The Netherlands

Full list of author information is available at the end of the article
}

hormone mediated, i.e. metabolic and sex hormones [3]. The evidence that oestrogens (endogenous as well as exogenous) contribute to breast cancer risk is strong and widely accepted [4-6]. Postmenopausal women with elevated levels of androgens also showed increased risk of developing breast cancer, even after adjustment for oestrogens [5-7]. In many cross-sectional observational studies, a low level of physical activity has been associated with higher serum concentrations of sex hormones in postmenopausal women [7-14], but not in all [15,16]. Physical activity might also influence postmenopausal sex hormones by increasing levels of sex hormone

\section{Biomed Central}

(c) 2013 van Gemert et al.; licensee BioMed Central Ltd. This is an Open Access article distributed under the terms of the Creative Commons Attribution License (http://creativecommons.org/licenses/by/2.0), which permits unrestricted use, distribution, and reproduction in any medium, provided the original work is properly cited. 
binding globulin (SHBG), resulting in lower amounts of unbound (free) active oestrogens and androgens in the circulation $[10,11,14,17]$.

The beneficial effect of exercise on breast cancer related biomarkers might be partly explained by exercise-induced fat loss and prevention of becoming overweight or obese. Observational studies show associations between body mass index (BMI) and oestrogen levels in postmenopausal women [8-12]. Compared with normal-weight women, obese postmenopausal women have a higher blood concentration of oestrogens $[12,13]$ and lower concentrations of SHBG resulting in increased levels of free oestradiol [12,14-16,18]. The association between BMI and androgens is less clear, i.e. crosssectional studies reported conflicting results [10,19-21].

In our previous SHAPE trial we found that in the exercise group, reductions of sex hormone levels mainly occur when concordant loss of body fat was achieved [22]. These findings were in concordance with results from a comparable exercise intervention study [23,24]. Another exercise intervention study [25], however, found an overall intervention effect of exercise on sex hormones, which might be explained by the fact that in this study the overall difference in weight reduction between the intervention and control group was much greater compared with the earlier trials. A fourth trial investigating the effects of dietary, exercise and combined weight loss interventions, found that greater weight loss produced stronger effects on oestrogens and SHBG [26].

The question remains whether the beneficial effect of physical activity on breast cancer risk is fully explained by the accompanied weight loss, or whether physical activity has an additional positive effect on hormones.

Therefore, we set out to study the effect of weight loss mainly driven by exercise compared with equivalent weight loss driven by a diet only, on breast cancer risk biomarkers. Furthermore, we are specifically interested whether weight loss due to physical exercise induces greater amounts of fat loss (total and abdominal) and subsequently results in stronger favourable effects on relevant hormones compared with equivalent diet-induced weight loss.

\section{Methods/design}

The aim of the SHAPE-2 study is to investigate the effect attributable to exercise on postmenopausal breast cancer risk biomarkers, when equivalent weight loss is achieved compared with diet-induced weight loss. The secondary aim is to study the effects of equivalent weight loss achieved by calorie reduced diet or by increased physical activity on body composition and fat distribution and whether this mediates sex hormone levels.

The SHAPE-2 study is designed as a three-armed, randomised controlled trial. The study programme runs in eight municipalities surrounding two research centres in the middle (Utrecht) and the east (Enschede) of the Netherlands. The total study duration for each study participant is about 21 weeks. After a 4-6 week run-in period, eligible women are randomly allocated to (1) a diet group; (2) an exercise group or (3) a waiting list control group. Both intervention groups have the aim to lose an amount of 5-6 kg of bodyweight in 10-14 weeks. The intervention period is followed by a weight maintenance period lasting at least 2 weeks.

The study protocol is approved by the Medical Ethics Committee of University Medical Centre Utrecht, in accordance with the Helsinki declaration, before the start of data collection.

\section{Study population}

A total of 250 postmenopausal women, aged 50-69 years, are included. Eligible women are overweight or obese (BMI $25-35 \mathrm{~m} / \mathrm{kg}^{2}$ ), have a sedentary lifestyle and live in the middle or east of the Netherlands.

Postmenopausal state is defined as natural cessation of menses for at least 12 months, or in case of hysterectomy: aged 55+ and likely to be postmenopausal based on medical history. Sedentary is defined as less than 2 hours of moderate-to-vigorous physical activity per week ( $\geq 4$ metabolic equivalents (MET)) [27]. Energy expenditure from occupational activity (except for highly active jobs e.g. courier, sports instructor), walking at moderate pace and cycling as a transport medium $(<16 \mathrm{~km} /$ hour$)$ are not considered. In case of doubt, individuals are discussed in the study team. Exclusion criteria are factors that either interfere with endogenous sex hormone levels or successful completion of the diet or exercise intervention (see Table 1).

\section{Recruitment and screening}

Study participants are mainly recruited by invitation letters explaining the study goals and inclusion criteria. These letters are sent to a random selection of female inhabitants (aged 50-69 years, Dutch nationality) of the participating municipalities: Zeist, Bilthoven, Utrecht, Nieuwegein, Houten, IJsselstein, Enschede, and Oldenzaal. Furthermore, we aim to publish articles in local newspapers including calls for participants. Responding women are contacted by phone by a study nurse to provide more information and to further assess eligibility. Potential candidates are invited for a screening visit at the research unit in their region, where informed consent is signed and BMI and glucose (ACCU-CHEK ${ }^{\circ}$ Aviva) are checked. Additionally, motivation and physical ability to perform the exercise programme are discussed. If eligible, the participant is scheduled for the study dietitian and starts with the run-in period. See Figure 1 for the flow chart of the recruitment and inclusion procedure. All participating women gave informed consent before start of the study. 
Table 1 SHAPE-2 study inclusion and exclusion criteria

\section{Inclusion criteria}

Female

50-69 years of age

Postmenopausal (last menses >12 months)

Body mass index (BMI) $25-35 \mathrm{~m} / \mathrm{kg}^{2}$

Sedentary lifestyle ( $<2$ hours/week of at least moderately intensive activities $(\geq 4 \mathrm{MET})$ )

Willing to be randomly assigned to one of the three study arms

Informed consent for all screening and study activities

\section{Exclusion criteria}

Presently using sex hormones

Use of beta-blockers or oral corticosteroids

Smoking

Alcohol or drug abuse

Diagnosed with breast cancer (present or history)

Diagnosed with other cancer (present or $<5$ years of history), except for non-melanoma skin cancer

Diabetes mellitus or other (unstable) endocrine related diseases

Any disorder that might impede participation in the exercise programme

Following, or intention to follow, a structured weight loss programme elsewhere

Investigators opinion (successful fulfilling of the programme is highly unlikely)

\section{Baseline diet during run in period}

During the 4-6 week run-in period, a baseline diet is prescribed which resembles the habitual intake of the participant and is in accordance with the Dutch Guidelines for a Healthy Diet [28] (50-60\% carbohydrate, 15$20 \%$ protein and $20-35 \%$ fat). The energy content of the baseline diet is determined using the individual's habitual energy intake (dietary history), body weight history and a calculated estimate using the Harris \& Benedict formula [29] multiplied by an estimate of their Physical
Activity Level (PAL). Special attention is paid to alcohol intake (maximum of one drink per day) and fibre intake (minimum of 25 grams per day) since these may influence sex hormone levels [30-32]. The run in period and the baseline diet aim to normalise the dietary pattern, stabilise body weight, check the estimated energy requirements and evaluate protocol adherence.

During the run-in, adherence to the programme is monitored by filling out a 3-day food diary, weekly self-weighing and telephone contacts with the dietitian (see Table 2).

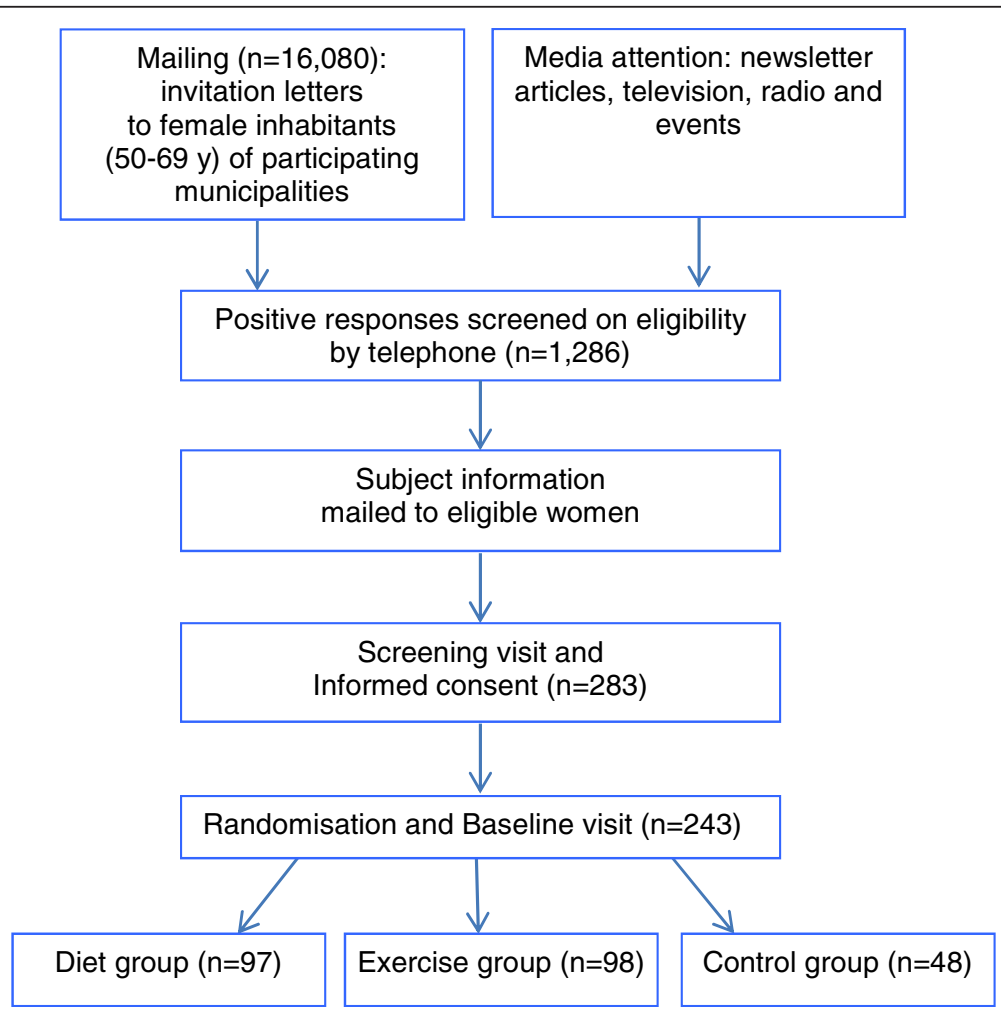

Figure 1 Flow-chart recruitment and inclusion procedure. 
Table 2 Overview study programme, contact moments and measurements

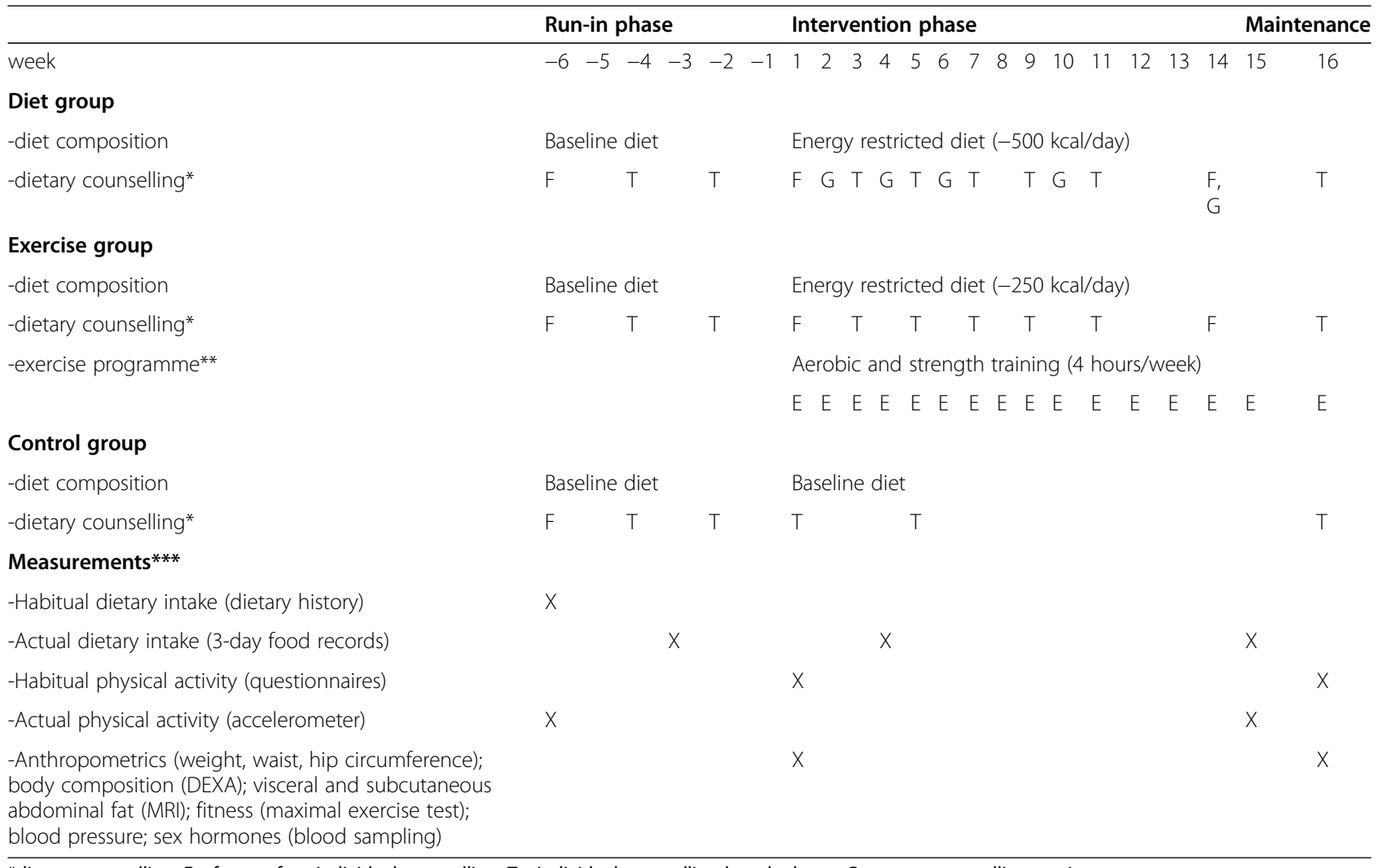

*dietary counselling: $\mathrm{F}$ = face-to-face individual counselling; $\mathrm{T}$ = individual counselling by telephone; $\mathrm{G}=$ group counselling session.

** exercise programme: $\mathrm{E}=$ group fitness and Nordic walking, 4 hours per week.

*** measurements: $\mathrm{X}=$ all participants.

\section{Randomisation \& intervention}

After successful completion of the run-in period, subjects are randomised to (1) a diet group; (2) an exercise group or (3) a waiting list control group. Randomisation is performed via a computer-generated sequence, stratified per municipality, in block sizes of 5 (ratio interventions vs. control; 2:2:1).

The goal of both intervention programmes is to lose an equivalent amount of 5-6 kg of body weight, in 1014 weeks' time. The weight loss interventions are supervised by dietitians and physiotherapists, established in each participating municipality.

Body weight is closely monitored in both intervention groups by continuation of weekly self-weighing. Supervised weighing, by the dietitian (at every visit) and physiotherapist (weekly), is performed in addition. Participants, whose weekly weight loss do not meet or exceed the $0.5 \mathrm{~kg} /$ week loss for 3 consecutive weeks, receive extra coaching to adapt their diet or exercise level.

If the weight loss goal is reached, or after a maximum of 14 weeks, a weight maintenance period (2-6 weeks) starts in which energy intake and energy expenditure is balanced by dietary adaptations. The goal of this maintenance period is to establish stable weight in order to obtain stable levels of sex hormones.

\section{Diet group: weight loss induced by diet only}

The weight loss intervention is delivered by registered dietitians, experienced in treatment of overweight and motivational interviewing. Motivational interviewing is a client-centred counselling approach which is a proven effective method used to increase motivation and to establish behaviour change [33,34].

Frequent contacts with the dietitian are scheduled (see Table 2 for an overview of the study programme). After randomisation, women individually meet their dietitian for the prescription of a calorie restricted diet. The diet has a deficit of $500 \mathrm{kcal} /$ day as compared with the individuals energy requirements estimated at the run-in period. The diet is composed of the same proportions of macronutrients as the baseline diet conform National Guidelines for a Healthy Diet [28]. Additionally, 5 onehour interactive group sessions are planned (maximal 12 women/group). The programme for these sessions is based on principles of cognitive behavioural therapy [35] and motivational interviewing [34] and consists of nutrition education, behaviour change techniques and self- 
management training. Adherence to the programme is monitored by completing a 3-day food diary and frequent telephone contacts with the dietitian (see Table 2). Women in the diet group are requested to maintain their habitual physical activity level.

\section{Exercise group: weight loss mainly induced by exercise}

Women randomised to the exercise group are enrolled in a 16-week exercise training programme, delivered by physiotherapists. Additionally, a moderate caloric restriction of $250 \mathrm{kcal} /$ day is prescribed by a dietitian in an individual session. From recent literature, we know that achieving and maintaining a body weight reduction by exercising in untrained and obese women is a long term process and a goal hard to attain [36,37]. Compensatory mechanisms both physically and mentally, and behavioural reasons withhold the person from losing weight adequately [38,39]. We, therefore, decided to study the effect of exercise in combination with a slight diet energy deficit.

The prescribed diet is monitored by regular telephone contacts with the dietitian. In this group, main emphasis is placed on the exercise programme, which contains four hours of moderate-to-vigorous exercise per week in groupand individual sessions. The estimated energy expenditure of the exercise programme is approximately $350 \mathrm{kcal} /$ day, based on corresponding MET rates [27]. For our specific study population, we corrected METs for age $[40,41]$.

The exercise protocol contains both endurance and strength training. Levels of exercise intensity are gradually increased during the study programme. Intensity of strength training is determined by pragmatic 20- and 15-repetition maximum (RM) tests, performed several times throughout the 16 weeks to adapt the resistance.

Intensity of endurance training is determined by the heart rate reserve based on the guidelines of the American College of Sports Medicine, adapted for older women [42]. Target heart rates are based on results of a maximal exercise test and calculated by the formula: [intensity\%*(maximal heart rate - resting heart rate)] + resting heart rate. Study participants wear heart rate monitors while exercising and receive a badge with individually calculated target heart rate zones for a range of training intensities.

During every training session, subjects fill in an exercise log which is used as a tool to adhere to the protocol and for monitoring by the physiotherapist.

\section{Group exercise}

Twice a week, subjects participate in a standardised onehour group session, facilitated by a physiotherapist. Groups consist of 5-6 women. The group exercise sessions include 20-25 minutes high-intensity endurance training combined with 25 minutes strength training. Classes start and end with a 5-10 minute warming up and cooling down, respectively.

Endurance training is performed in circuits on several exercise machines, e.g. a treadmill, cycle or cross-trainer. Intensity is gradually increased (see Table 3 ).

The standardised strength training protocol includes exercises for the major muscle groups which is also performed in circuits (Table 3).

\section{Individual exercise}

For feasibility reasons, individual home-based exercise is also included. It comprises two hours of Nordic walking at $60-65 \%$ of the heart rate reserve. All participants receive Nordic walking poles and instructions. If due to medical reasons Nordic walking is not desirable, a proper alternative is sought, e.g. swimming laps or cycling (vigorous effort). Supervised lessons of Nordic walking by instructors are organised to increase motivation and compliance. These sessions can be attended voluntarily, however, women are strongly encouraged to join.

Home-based Nordic walking sessions are registered in an exercise-log, which are checked regularly by the physiotherapist. Group sessions at the physiotherapists office and Nordic walking lessons are regularly monitored by the researchers.

\section{Table 3 Group fitness training programme}

\begin{tabular}{|c|c|c|}
\hline Week & Endurance & Strength \\
\hline $1-3$ & $40-60 \% \mathrm{HRR}^{*}$ & 1 circuit of $20-25$ repetitions. Weights based on $20-\mathrm{RM}^{\#}$ \\
\hline \multirow[t]{2}{*}{$4-8$} & 60-70\% HRR* 15-20 min, & \multirow{2}{*}{$\begin{array}{l}\text { Exercises: legs (squat, lunges, calve raises), arms (biceps curl, } \\
\text { triceps extension), shoulder (shoulder press), thorax } \\
\text { (Barbell bench press), back (rowing). Abdomen: crunch 30-40 repetitions. }\end{array}$} \\
\hline & Plus $70-89 \% \mathrm{HRR}^{*}$ 5-10 min & \\
\hline \multirow[t]{3}{*}{$9-12$} & \multirow{2}{*}{$\begin{array}{l}\text { Interval training: } 10 \times 30 \mathrm{sec} \text {. vigorous to maximal exercise, } \\
\text { alternated with } 1 \mathrm{~min} \text { active rest }\end{array}$} & \multirow{5}{*}{$\begin{array}{l}2 \text { circuits of 15-20 repetitions. Weights based on 15-RM }{ }^{\#} \\
\text { Exercises: legs (squat), arms (biceps curl, triceps extension), shoulder } \\
\text { (shoulder press), thorax (Barbell bench press), back (rowing). } \\
\text { Abdomen; crunch } 30-40 \text { repetitions; hoover } 2 \times 45 \text { seconds. } \\
\text { If in time calve raises and lunges can be added. }\end{array}$} \\
\hline & & \\
\hline & Plus 10 min $60-75 \% \mathrm{HRR}^{*}$ endurance & \\
\hline \multirow[t]{2}{*}{$\begin{array}{l}13- \\
16\end{array}$} & $\begin{array}{l}\text { Interval training: } 2 \text { circuits of } 8 \times 30 \mathrm{sec} \text { vigorous to maximal, } \\
\text { alternated with } 1 \text { min active rest }\end{array}$ & \\
\hline & Plus 5 min $60-75 \% \mathrm{HRR}^{*}$ endurance & \\
\hline
\end{tabular}




\section{Control group: stable weight}

Participants in the control group are requested to keep their weight stable by adhering to the baseline diet, and maintaining their habitual exercise pattern. They are offered an alternative weight loss programme after the study period, consisting of 4 dietary group sessions and several exercise classes such as Nordic walking and/or fitness.

\section{Outcomes and measurements}

Study participants visit the research centre for measurements twice: at baseline (i.e. the end of the run-in period) and at the end of the study (see Table 2). Measurements include blood sampling, anthropometrics: height (at baseline), weight, waist- and hip circumference), a total body DEXA scan, abdominal MRI, blood pressure and cardiorespiratory fitness. At every visit, information on medication use is assessed. Furthermore, we assess information on socio-demographic variables, general health, medical history, reproductive history and smoking history at baseline by a self-constructed questionnaire.

\section{Blood samples}

Blood samples $(30 \mathrm{ml})$ are drawn in order to determine serum concentrations of oestradiol (total and free), oestrone, testosterone and SHBG. After centrifugation, samples are directly stored at $-20^{\circ} \mathrm{C}$ and at $-80^{\circ} \mathrm{C}$ within one week. All samples from one individual will be analysed in the same batch since the batch-to-batch variation can be higher than any woman's likely change in hormones over the year [43]. Serum oestrogens and testosterone will be determined by use of the LC-MS method, in the UHSM, Manchester laboratory [44]. SHBG will be measured by commercially available double-antibody radioimmunoassay kits (Roche Cobas: SHBG03052001), performed in the laboratory "Stichting Huisartsenlaboratorium Oost" in Velp [45]. Technicians are blinded to study allocation.

\section{Anthropometrics and body composition}

Body weight and height are measured while the subjects wear light clothes without shoes. To measure body weight, we use calibrated analogue balance and digital balance scales $\left(\mathrm{SECA}^{\odot}\right)$, depending on study centre. Subjects are always measured on the same balance scale. Analogue values are rounded to the nearest $0.5 \mathrm{~kg}$. Height is measured using a wall mounted tape measure and rounded to the nearest $0.5 \mathrm{~cm}$.

Waist circumference (to the nearest $0.5 \mathrm{~cm}$ ) is measured standing at the midway between lower ribs and iliac crest. Hip circumference (to the nearest $0.5 \mathrm{~cm}$ ) is measured standing over the buttocks. All measurements are taken in duplicate and averaged.

Total body fat $(\mathrm{kg})$ and fat percentage (\%) are assessed by a total body DEXA-scan (Lunar, Prodigy ${ }^{\mathrm{TM}}$ ). The DEXA scan measures body composition according to a threecompartment model: fat mass, lean tissue, and bone mineral content. The standard soft tissue analysis is performed using software supplied by the manufacturer.

Visceral abdominal fat (VAT) and subcutaneous abdominal fat (SAT) are measured by MRI (Philips, Ingenia $1.5 \mathrm{~T}$ ) with the use of the three-point IDEAL method, described by Dixon [46].

\section{Blood pressure}

Blood pressure is measured by an automatic tonometer (OMRON M4 +) after a minimum of 5 minutes rest. Measurements are taken twice, with a 2-minute time interval.

\section{Cardiorespiratory fitness}

A maximal cycle exercise test with respiratory gas analysis is performed to measure cardiorespiratory fitness, defined by the highest oxygen uptake during the test $\left(\mathrm{VO}_{2 \text { peak }}\right)$.

All testing is conducted according to the ATS guidelines [47]. Subjects are tested on a bicycle ergometer (Ergoline, type Ergoselect 200 P, CareFusion, Houten, the Netherlands and Jaeger ER800 ${ }^{\circ}$ Würtzburg, Germany). Seat height is adjusted so that subject's legs are near full extension during each pedal revolution.

The ramp cycle test protocol starts with 2 minutes of rest and 3 minutes of active rest (cycling without workload). The test phase consists of 24-second stages of graded exercise. Workload increases with 12.5 Watt or 15 Watt at every step, depending on the predicted maximum Watt per subject. Pedalling speed is kept around 65 revolutions per minute (RPM). If participants fail to keep up or drop below 40 RPM, the test is ended and followed by a 2-minute recovery phase. The maximal exercise test is performed under medical supervision. During the test, a 12-lead electrocardiogram (ECG) and respiratory data through breath-by-breath analysis (Oxycon Pro ${ }^{\oplus}$, Jaeger, by Care Fusion, Houten, The Netherlands) are continuously measured. Heart rate is determined from the ECG. Cuff blood pressure is monitored before and throughout the exercise and recovery phase. $\mathrm{VO}_{2 \text { peak }}$ is defined as the highest 15-second average of $\mathrm{VO}_{2}$ obtained at the end of the test and is expressed as $\mathrm{ml} / \mathrm{min}$ and $\mathrm{ml} / \mathrm{kg} / \mathrm{min}$.

The goal of the maximal cycle exercise test is threefold. In addition to measuring cardiorespiratory fitness/ $\mathrm{VO}_{2 \text { peak }}$, it also serves as a medical evaluation, and maximal heart rate is used to estimate training intensity for women participating in the exercise programme.

\section{Physical activity}

Physical activity level is assessed with an activity monitor $\left(\right.$ GT3X + Tri-Axis Actigraphy Monitor, ActiGraph $\left.{ }^{\oplus}\right)$. This non-invasive device provides information on individual 
activity including energy expenditure, sedentary behaviour, activity intensity levels, and METs. It is worn in 7 consecutive days during the run-in and maintenance period.

Furthermore, validated physical activity questionnaires are used to measure habitual activity level (PASE questionnaire) [48] and short-term physical activity level (SQUASH questionnaire) [49] at baseline and at the end of study.

\section{Dietary intake}

Habitual dietary intake is assessed at baseline using the dietary history method. Actual dietary intake and adherence to the diet plan are assessed using 3-day food records (including 1 weekend day) during every study period (run-in, intervention and maintenance, see Table 2). Participants are instructed by the dietitian how to complete the records. Filled-in records are checked by the dietitian for completeness and can be discussed with participants in the next telephone contact. Energy intake and nutrient composition are calculated using the Dutch Food Composition Database [50].

\section{Sample size}

Sample size calculations are based on the effect of the interventions on the primary outcome, i.e. serum oestradiol levels. The following comparisons will be made:

1) diet-induced weight loss versus exercise-induced weight loss. 2) diet-induced weight loss versus control. 3) exercise-induced weight loss versus control. First, we calculated the sample size for the first comparison, i.e. dietinduced weight loss $(n=85)$ versus exercise-induced weight loss $(n=85)$, since the difference in oestradiol levels between these groups is expected to be the smallest (8\%). Based on the estimated sample sizes, we calculated the number of subjects needed in the control group ( $\mathrm{n}=$ 36). The sample size of the control group can be much smaller, since the expected difference with the interventions groups is large ( $12 \%$ and $20 \%$, respectively). The sample size calculations resulted in the following estimated numbers per group, taking into account 5\% drop out and 15\% non-compliance: control group $n=45$, diet group $n=104$ and exercise group $n=104$.

\section{Statistical analysis}

Descriptive statistics will be used to characterise the study population at baseline per study arm. Baseline and end of study values of sex hormone levels, total body fat and intra-abdominal body fat will be tabulated by treatment group. Sex hormones will be log transformed and geometric means will be presented if not normally distributed.

The main analysis will be performed according to the intention-to-treat principle, by linear regression analysis, where outcomes for patients are analysed by assigned treatment, regardless of the level of adherence. As a secondary analysis, adherence will be examined as a potential modifier of the intervention effects.

A per-protocol analysis will be performed analysing women who reached the weight loss goal only. Whether changes in body fat (total, abdominal) mediate or moderate intervention effects on sex hormone levels will be explored.

\section{Discussion}

In the SHAPE-2 study, we aim to investigate the potential effect of physical activity on biomarkers of breast cancer risk (sex hormones), additional to weight loss. We hypothesize that exercise-induced weight loss results in a stronger decrease in serum sex hormones compared with equivalent diet-induced weight loss and compared with controls.

The goal of the intervention, and challenge in this trial, is for subjects to lose an equivalent amount of 5$6 \mathrm{~kg}$ of body weight in both intervention groups. Success of the study depends heavily on subjects' adherence and motivation.

We implemented several strategies to increase adherence and motivation of the study subjects. First, the weight loss interventions are delivered by experienced dietitians and physiotherapists, who are situated in the municipality and easily accessible. For participants in the intervention groups, we scheduled a high contact frequency with the dietitian and physiotherapists which is proven to be a relevant success factor for weight reduction [51]. Second, group sessions are implemented in both intervention programmes which provide a combination of social support, a healthy dose of competition and increase self-efficacy [52]. It is also suggested that dietary group sessions produce greater weight loss effects than individual counselling alone [53]. Groups are kept small to secure enough room for interactions and tailoring of the programme to the specific needs of the participants. Third, to strengthen motivation of the participants and for monitoring purposes, the researchers visit diet and exercise group sessions regularly. Furthermore, participants receive newsletters about the study or related topics and the study website is updated frequently.

Adherence of the control group is also a challenge. We expect women allocated to the control group to be disappointed since they have their mind set on losing weight. This might lead to a change in lifestyle, either conscious or unconscious, resulting in slight weight loss. To anticipate, we repeatedly stress the importance of the control group. Moreover, we offer an evenly attractive alternative weight loss programme starting at the end of the study. 
This trial has a strict time schedule. We aim to include 25-30 participants per municipality in a small time window, since the participants have to start simultaneously with the group interventions. The first group starts at the central research site in the Utrecht region. Inclusion in the second participating region (Enschede) starts in parallel. Consecutive groups within one region start after a minimum time interval of 1 month.

Due to a consecutive inclusion of municipalities, the winter season, summer holidays and national holidays (e.g. Christmas) might affect the adherence of some study groups. To retain compliance in order to achieve the same weight loss goal, dietitians and physiotherapists will anticipate these circumstances. We pay extra attention to the Nordic walking programme in winter since the colder climate and shorter days may threat compliance. We therefore provide more options for supervised Nordic walking hours and reflective clothing in winter.

In our study, we will measure visceral and subcutaneous abdominal fat by using MRI, which is a highly sensitive technique to measure changes in (intra-)abdominal fat. A side effect of the use of cross sectional imaging in healthy subjects is that there is a risk of incidental findings. Rates of over $30 \%$ have been described while the proportion of subjects that might benefit from these findings is likely to be much lower than the proportion that will have no or even an adverse effect [54,55]. Outweighing the riskbenefit ratio and ethical considerations [56], we decided on the following procedure. The non-contrast enhanced T1-weighted IDEAL scans are considered non-diagnostic and therefore will not be routinely reviewed by a radiologist. If researchers encounter an apparent finding that strikes them as a possible abnormality, the radiologist will be consulted. When the finding is of potential clinical relevance, the participant and their general practitioner will be informed and advised on further work up.

Our trial is the first study especially designed to assess the additional effect of exercise on sex hormone levels when equivalent weight loss is achieved. Four former exercise intervention studies in the field suggested an interplay between sex hormones and body weight/fat mass [22-26]. Greater weight loss produced greater effects on serum sex hormone levels and SHBG.

The question remains whether there is an additional effect of exercise on serum sex hormones, as breast cancer risk biomarkers, when equivalent weight loss is reached. In the SHAPE-2 study, we aim to investigate the potential effect attributable to physical activity on postmenopausal breast cancer risk biomarkers, in addition to weight loss.

\section{Competing interests}

This work is supported by the Dutch Cancer Society [UU 2010-4843]. The support from the sponsor is unconditional, and the data collection, design, management, analysis, interpretation and reporting will be performed without their interference. We have no non-financial competing interests to disclose.

\section{Authors' contributions}

Authors WG, JI, PP, AS, AM, TT, JP and EM were involved in the study design. $\Pi$, advised in the composition of the exercise programme. Jl, EM and WG composed the dietary programme. WV designed the MRI scan protocol. HW supplied services and materials for exercise testing. WG, EM, PP and JS participated in the management and coordination of the study. JP participated in the coordination on the second research site. WG and EM drafted the manuscript. All have been involved in revising the content of the manuscript. All authors have read and approved the final manuscript.

\section{Authors' information}

Willemijn van Gemert, MD, works as a PhD candidate at the department of epidemiology of the Julius Center. Jolein lestra, $\mathrm{PhD}$, is a dietitian at the department of Public Health of the Julius Center. Petra Peeters, MD, PhD, Evelyn Monninkhof, PhD, and Anne May, PhD are epidemiologists working at the epidemiology department of the Julius Center. Albertine Schuit, PhD, is an epidemiologist at the national institute of Health and VU university. Tim Takken, PhD, is an exercise physiologist working at the UMC Utrecht. Wouter B. Veldhuis, $\mathrm{MD}, \mathrm{PhD}$, is a radiologist working at the radiology department of the UMC Utrecht. Job van der Palen, PhD, is an epidemiologist and works as a scientific research coordinator in the Medical Spectrum Twente and as a professor in evaluation and assessment in healthcare research at the University Twente. Harriët Wittink, PhD, is a physiotherapist and professor Lifestyle and Health at the faculty of health care, Utrecht University of Applied Sciences.

\section{Acknowledgements}

We would like to acknowledge the following people who have collected data or contributed to the running of the study: Manon de Leeuw, Fien Stern, Lydeke Zwart, Lizeth Vendrig, Marjon van der Meer, Gerry van Hemert, Karen Menninga, Joke metselaars, Veronique Sauerwald, Renate Bloemen Willemien Boersma, Silvia Achterberg, Petra Hemeltjen, Mirjam Floor, Roelof Peters and Jolanda Spruit. We would like to thank Ria Bouwhuis, who as a dietetic student was involved in composing the diet programme.

Furthermore, we would greatly like to thank all the study participants and the participating physiotherapists and dietitians in Utrecht and Enschede and surroundings.

This work was supported by the Dutch Cancer Society [UU 2003-2793] and the Dutch Pink Ribbon Foundation [PR1 10032, PR110039]. The support from the sponsors was unconditional, and the data collection, design,

management, analysis, interpretation and reporting were performed without their interference.

\section{Author details}

'Julius Center for Health Sciences and Primary Care, University Medical Center Utrecht, P.O. Box 85500 Hp, Str. 6.131, 3508 GA, Utrecht, The Netherlands. ${ }^{2}$ Division of Public Health and Health Care, National Institute for Public Health and the Environment, P.O. Box 13720 BA, Bilthoven, The Netherlands. ${ }^{3}$ Department of Health Sciences and EMGO Institute for Health and Care Research, VU University, Amsterdam, The Netherlands. ${ }^{4}$ Shared Utrecht Pediatric Exercise Research (SUPER) Lab, Utrecht University, Utrecht, The Netherlands. ${ }^{5}$ Child Development \& Exercise Center, Wilhelmina Children's Hospital, University Medical Center Utrecht, P.O. Box 85500 Hp, Str. 6.131, 3508 GA, Utrecht, The Netherlands. ${ }^{6}$ Department of Radiology, University Medical Center, P.O. Box 85500 Hp, Str. 6.131, 3508 GA, Utrecht, The Netherlands. ${ }^{7}$ Medisch Spectrum Twente Hospital, Department of Epidemiology, P.O. Box 500007500 KA, Enschede, The Netherlands. ${ }^{8}$ Department of Research Methodology, Measurement, and Data Analysis, University of Twente, Enschede, The Netherlands. ${ }^{9}$ Research group Lifestyle and Health, Faculty of Health Care, Utrecht University of Applied Sciences, P.O. Box 851823508 AD, Utrecht, The Netherlands.

Received: 2 May 2013 Accepted: 21 August 2013

Published: 23 August 2013

\section{References}

1. World Cancer Research Fund, American Institute for Cancer Research: Food, Nutrition, Physical Activity, and the Prevention of Cancer: a Global Perspective. Washington DC: AICR; 2007. 
2. Monninkhof EM, Elias SG, Vlems FA, van der Tweel I, Schuit AJ, Voskuil DW, van Leeuwen FE: Physical activity and breast cancer: a systematic review. Epidemiology 2007, 18:137-157.

3. Campbell KL, McTiernan A: Exercise and biomarkers for cancer prevention studies. J Nutr 2007, 137:161S-169S.

4. Hankinson SE, Eliassen AH: Endogenous estrogen, testosterone and progesterone levels in relation to breast cancer risk. J Steroid Biochem Mol Biol 2007, 106:24-30.

5. Kaaks R, Rinaldi S, Key TJ, Berrino F, Peeters PH, Biessy C, Dossus L, Lukanova A, Bingham S, Khaw KT, et al: Postmenopausal serum androgens, oestrogens and breast cancer risk: the European prospective investigation into cancer and nutrition. Endocr Relat Cancer 2005, 12:1071-1082.

6. Key T, Appleby P, Barnes I, Reeves G: Endogenous sex hormones and breast cancer in postmenopausal women: reanalysis of nine prospective studies. J Nat/ Cancer Inst 2002, 94:606-616.

7. Tamimi RM, Byrne C, Colditz GA, Hankinson SE: Endogenous hormone levels, mammographic density, and subsequent risk of breast cancer in postmenopausal women. J Natl Cancer Inst 2007, 99:1178-1187.

8. Nelson ME, Meredith CN, Dawson-Hughes B, Evans WJ: Hormone and bone mineral status in endurance-trained and sedentary postmenopausal women. J Clin Endocrinol Metab 1988, 66:927-933.

9. McTiernan A, Wu L, Chen C, Chlebowski R, Mossavar-Rahmani Y, Modugno F, Perri MG, Stanczyk FZ, Van HL, Wang CY: Relation of BMI and physical activity to sex hormones in postmenopausal women. Obesity (Silver Spring) 2006, 14:1662-1677.

10. Cauley JA, Gutai JP, Kuller LH, LeDonne D, Powell JG: The epidemiology of serum sex hormones in postmenopausal women. Am J Epidemiol 1989, 129:1120-1131.

11. Chan MF, Dowsett M, Folkerd E, Bingham S, Wareham N, Luben R, Welch A, Khaw KT: Usual physical activity and endogenous sex hormones in postmenopausal women: the European prospective investigation into cancer-norfolk population study. Cancer Epidemiol Biomarkers Prev 2007 16:900-905

12. Schmitz KH, Lin H, Sammel MD, Gracia CR, Nelson DB, Kapoor S, DeBlasis TL, Freeman EW: Association of physical activity with reproductive hormones: the Penn ovarian aging study. Cancer Epidemiol Biomarkers Prev 2007, 16:2042-2047.

13. Madigan MP, Troisi R, Potischman N, Dorgan JF, Brinton LA, Hoover RN: Serum hormone levels in relation to reproductive and lifestyle factors in postmenopausal women (United States). Cancer Causes Control 1998, 9:199-207.

14. Van Gils CH, Peeters PH, Schoenmakers MC, Nijmeijer RM, Onland-Moret NC, van der Schouw YT, Monninkhof EM: Physical activity and endogenous sex hormone levels in postmenopausal women: a cross-sectional study in the prospect-EPIC cohort. Cancer Epidemiol Biomarkers Prev 2009, 18:377-383

15. Bjornerem A, Straume B, Midtby M, Fonnebo V, Sundsfjord J, Svartberg J, Acharya G, Oian P, Berntsen GK: Endogenous sex hormones in relation to age, sex, lifestyle factors, and chronic diseases in a general population: the tromso study. J Clin Endocrinol Metab 2004, 89:6039-6047.

16. Verkasalo PK, Thomas HV, Appleby PN, Davey GK, Key TJ: Circulating levels of sex hormones and their relation to risk factors for breast cancer: a cross-sectional study in 1092 pre- and postmenopausal women (United Kingdom). Cancer Causes Control 2001, 12:47-59.

17. Wu F, Ames R, Evans MC, France JT, Reid IR: Determinants of sex hormone-binding globulin in normal postmenopausal women. Clin Endocrinol (Oxf) 2001, 54:81-87.

18. Renehan AG, Tyson M, Egger M, Heller RF, Zwahlen M: Body-mass index and incidence of cancer: a systematic review and meta-analysis of prospective observational studies. Lancet 2008, 371:569-578.

19. Bezemer ID, Rinaldi S, Dossus L, Gils CH, Peeters PH, Noord PA, Bueno-deMesquita HB, Johnsen SP, Overvad K, Olsen A, et al: C-peptide, IGF-I, sexsteroid hormones and adiposity: a cross-sectional study in healthy women within the European prospective investigation into cancer and nutrition (EPIC). Cancer Causes Control 2005, 16:561-572.

20. Kaye SA, Folsom AR, Soler JT, Prineas RJ, Potter JD: Associations of body mass and fat distribution with sex hormone concentrations in postmenopausal women. Int J Epidemiol 1991, 20:151-156.

21. Newcomb PA, Klein R, Klein BE, Haffner S, Mares-Perlman J, Cruickshanks KJ, Marcus PM: Association of dietary and life-style factors with sex hormones in postmenopausal women. Epidemiology 1995, 6:318-321.
22. Monninkhof EM, Velthuis MJ, Peeters PH, Twisk JW, Schuit AJ: Effect of exercise on postmenopausal sex hormone levels and role of body fat: a randomized controlled trial. J Clin Oncol 2009, 27:4492-4499.

23. McTiernan A, Tworoger SS, Ulrich CM, Yasui Y, Irwin ML, Rajan KB, Sorensen B, Rudolph RE, Bowen D, Stanczyk FZ, et al: Effect of exercise on serum estrogens in postmenopausal women: a 12-month randomized clinical trial. Cancer Res 2004, 64:2923-2928.

24. McTiernan A, Tworoger SS, Rajan KB, Yasui Y, Sorenson B, Ulrich CM, Chubak J, Stanczyk FZ, Bowen D, Irwin ML, et al: Effect of exercise on serum androgens in postmenopausal women: a 12-month randomized clinical trial. Cancer Epidemiol Biomarkers Prev 2004, 13:1099-1105.

25. Friedenreich CM, Woolcott CG, McTiernan A, Ballard-Barbash R, Brant RF, Stanczyk FZ, Terry T, Boyd NF, Yaffe MJ, Irwin ML, et al: Alberta physical activity and breast cancer prevention trial: sex hormone changes in a year-long exercise intervention among postmenopausal women. J Clin Oncol 2010, 28:1458-1466.

26. Campbell KL, Foster-Schubert KE, Alfano CM, Wang CC, Wang CY, Duggan CR, Mason C, Imayama I, Kong A, Xiao L, et al: Reduced-calorie dietary weight loss, exercise, and sex hormones in postmenopausal women: randomized controlled trial. J Clin Oncol 2012, 30:2314-2326.

27. Ainsworth BE, Haskell WL, Herrmann SD, Meckes N, Bassett DR Jr, TudorLocke C, Greer JL, Vezina J, Whitt-Glover MC, Leon AS: Compendium of physical activities: a second update of codes and MET values. Med SCi Sports Exerc 2011, 2011(43):1575-1581.

28. Health Council of the Netherlands: Guidelines for a healthy diet 2006. Health Council of the Netherlands: The Hague; 2006. publication no. 2006/21E.

29. Roza AM, Shizgal HM: The Harris Benedict equation reevaluated: resting energy requirements and the body cell mass. Am J Clin Nutr 1984, 40:168-182.

30. Onland-Moret NC, Peeters PH, van der Schouw YT, Grobbee DE, Van Gils CH: Alcohol and endogenous sex steroid levels in postmenopausal women: a cross-sectional study. J Clin Endocrinol Metab 2005, 90:1414-1419.

31. Rinaldi S, Peeters PH, Bezemer ID, Dossus L, Biessy C, Sacerdote C, Berrino F, Panico S, Palli D, Tumino R, et al: Relationship of alcohol intake and sex steroid concentrations in blood in pre- and post-menopausal women: the European prospective investigation into cancer and nutrition. Cancer Causes Control 2006, 17:1033-1043.

32. Wayne SJ, Neuhouser ML, Ulrich CM, Koprowski C, Baumgartner KB, Baumgartner RN, McTiernan A, Bernstein L, Ballard-Barbash R: Dietary fiber is associated with serum sex hormones and insulin-related peptides in postmenopausal breast cancer survivors. Breast Cancer Res Treat 2008, 112:149-158.

33. Armstrong MJ, Mottershead TA, Ronksley PE, Sigal RJ, Campbell TS, Hemmelgarn BR: Motivational interviewing to improve weight loss in overweight and/or obese patients: a systematic review and metaanalysis of randomized controlled trials. Obes Rev 2011, 12:709-723.

34. Miller WR, Rollnick S: Motivational interviewing: helping people change. New York: Guilford Press; 2012

35. Shaw K, O'Rourke P, Del MC, Kenardy J: Psychological interventions for overweight or obesity. Cochrane Database Syst Rev 2005, 2:CD003818.

36. Foster-Schubert KE, Alfano CM, Duggan CR, Xiao L, Campbell KL, Kong A, Bain CE, Wang CY, Blackburn GL, McTiernan A: Effect of diet and exercise, alone or combined, on weight and body composition in overweight-to -obese postmenopausal women. Obesity (Silver Spring) 2012, 20:1628-1638

37. Velthuis MJ, Schuit AJ, Peeters PH, Monninkhof EM: Exercise program affects body composition but not weight in postmenopausal women. Menopause 2009, 16:777-784.

38. King NA, Caudwell P, Hopkins M, Byrne NM, Colley R, Hills AP, Stubbs JR, Blundell JE: Metabolic and behavioral compensatory responses to exercise interventions: barriers to weight loss. Obesity (Silver Spring) 2007, 15:1373-1383

39. Blundell JE, Stubbs RJ, Hughes DA, Whybrow S, King NA: Cross talk between physical activity and appetite control: does physical activity stimulate appetite? Proc Nutr Soc 2003, 62:651-661.

40. Byrne NM, Hills AP, Hunter GR, Weinsier RL, Schutz Y: Metabolic equivalent: one size does not fit all. J Appl Physiol 2005, 99:1112-1119.

41. Kozey S, Lyden K, Staudenmayer J, Freedson P: Errors in MET estimates of physical activities using $3.5 \mathrm{ml} \times \mathrm{kg}(-1) \times \min (-1)$ as the baseline oxygen consumption. J Phys Act Health 2010, 7:508-516.

42. Kohrt WM, Spina RJ, Holloszy JO, Ehsani AA: Prescribing exercise intensity for older women. J Am Geriatr Soc 1998, 46:129-133. 
43. Tworoger SS, Yasui Y, Chang L, Stanczyk FZ, McTiernan A: Specimen allocation in longitudinal biomarker studies: controlling subject-specific effects by design. Cancer Epidemiol Biomarkers Prev 2004, 13:1257-1260.

44. Haring R, Hannemann A, John U, Radke D, Nauck M, Wallaschofski H, Owen L, Adaway J, Keevil BG, Brabant G: Age-specific reference ranges for serum testosterone and androstenedione concentrations in women measured by liquid chromatography-tandem mass spectrometry. J Clin Endocrinol Metab 2012, 97:408-415.

45. Stichting Huisartsenlaboratorium Oost. www.labsho.nl.

46. Dixon WT: Simple proton spectroscopic imaging. Radiology 1984 153:189-194.

47. American Thoracic Society: American College of Chest Physicians. ATS/ ACCP Statement on cardiopulmonary exercise testing. Am J Respir Crit Care Med 2003, 167:211-277.

48. Wendel-Vos GC, Schuit AJ, Saris WH, Kromhout D: Reproducibility and relative validity of the short questionnaire to assess health-enhancing physical activity. J Clin Epidemiol 2003, 56:1163-1169.

49. Schuit AJ, Schouten EG, Westerterp KR, Saris WH: Validity of the physical activity scale for the elderly (PASE): according to energy expenditure assessed by the doubly labeled water method. J Clin Epidemiol 1997, 50:541-546.

50. Dutch Food Composition Database; 2011. NEVO online version 2011/3.0, RIVM, Bilthoven. http://nevo-online.rivm.nl/.

51. Dansinger ML, Tatsioni A, Wong JB, Chung M, Balk EM: Meta-analysis: the effect of dietary counseling for weight loss. Ann Intern Med 2007, 147:41-50.

52. Ashford S, Edmunds J, French DP: What is the best way to change selfefficacy to promote lifestyle and recreational physical activity? a systematic review with meta-analysis. Br J Health Psychol 2010, 15:265-288.

53. Renjilian DA, Perri MG, Nezu AM, McKelvey WF, Shermer RL, Anton SD: Individual versus group therapy for obesity: effects of matching participants to their treatment preferences. J Consult Clin Psychol 2001, 69:717-721.

54. Orme NM, Fletcher JG, Siddiki HA, Harmsen WS, O'Byrne MM, Port JD, Tremaine WJ, Pitot HC, McFarland EG, Robinson ME, et al: Incidental findings in imaging research: evaluating incidence, benefit, and burden. Arch Intern Med 2010, 170:1525-1532.

55. Pinato DJ, Stavraka C, Tanner M, Esson A, Jacobson EW, Wilkins MR, Libri V: Clinical, ethical and financial implications of incidental imaging findings: experience from a phase I trial in healthy elderly volunteers. PLOS One 2012, 7:e49814.

56. Wolf SM, Lawrenz FP, Nelson CA, Kahn JP, Cho MK, Clayton EW, Fletcher JG, Georgieff MK, Hammerschmidt D, Hudson K, et al: Managing incidental findings in human subjects research: analysis and recommendations. J Law Med Ethics 2008, 36:219-248. 211.

doi:10.1186/1471-2407-13-395

Cite this article as: van Gemert et al:: Design of the SHAPE-2 study: the effect of physical activity, in addition to weight loss, on biomarkers of postmenopausal breast cancer risk. BMC Cancer 2013 13:395.

\section{Submit your next manuscript to BioMed Central and take full advantage of:}

- Convenient online submission

- Thorough peer review

- No space constraints or color figure charges

- Immediate publication on acceptance

- Inclusion in PubMed, CAS, Scopus and Google Scholar

- Research which is freely available for redistribution 